\title{
Crisis management and distrust: Study of an industrial accident in France
}

\author{
Elsa Negre \\ Paris-Dauphine University, PSL Research Universities, CNRS UMR 7243, LAMSADE, 75016 Paris, France \\ elsa.negre@lamsade.dauphine.fr
}

\begin{abstract}
Most crises, whether ecological, humanitarian, economic or even social, are preceded by various warning signals which make it possible to trigger alerts. These alerts make it possible to prevent or limit human and material damage if they are delivered on time and if they allow stakeholders (decision-makers, populations, etc.) to prepare adequately for the coming crisis. Today, there are many systems that can pick up the warning signals of crises to limit their consequences. Warning systems are one of them, they have proven their effectiveness, but as with any system involving populations, a part of unpredictable remains. In this article, we are interested in industrial accidents and in particular the fire at the Lubrizol factory in Rouen (France), classified SEVESO, in September 2019. Following interviews with the population of the Rouen's agglomeration, we set an example of distrust of public authorities' decisions and give some leads on how an information system could reconcile populations and decision-makers.
\end{abstract}

\section{Introduction}

In 2016, the global community invested nearly \$27 billion in humanitarian assistance to help people affected by crises (mainly in response to floods, droughts, storms, earthquakes or epidemics) [1]. This aid continues to increase in large part to respond to the increase of natural disasters. In fact, more than 1,100 natural disasters were recorded in 2017 around the world according to the Natural Disaster Observatory, compared to only 599 in 2002. Globally, a growing number of professionals and volunteers are trying to help limit the consequences of crises, in terms of number of lives lost, economic damages and people affected [2], but these continue to grow.

In France, natural risks: floods, marine submersions and coastal erosion, storms and cyclones, earthquakes, ground movements, forest fires, volcanic eruptions and avalanches, etc. and technological risks: industrial or nuclear risks, transport of dangerous materials, mining risks, dam failures, etc. are spread all over the territory. Between 1982 and 2016, four fifths of French municipalities were recognized in a state of natural disaster at least once, representing a total of 107,700 recognitions of municipalities in a state of natural disaster [3].

Despite the growing number of publications and knowledge acquired on risk, the vulnerability of populations, resilience and warning systems, crisis management practices remain extremely delicate subjects to think about and implement [4]. Indeed, on the one hand, crises are considered as exceptional events, and on the other hand, to manage a crisis, a significant number of actors must act on red flags which are often the result of an analysis of complex processes. However, the greater the complexity of the processes and the greater the number of actors and from different cultures, the more difficult it will be to manage a crisis.

\section{Crises and populations}

Modern societies are increasingly fragile in the face of crises. In global risk management, measures to reduce this vulnerability are therefore increasingly proposed. Here, we are interested in measures to reduce social vulnerability, which concern in particular the ability of populations to face risk through their behaviour. We consider here the behaviour of populations in reaction to an alert or a crisis as a factor of vulnerability of societies but also as an issue of resilience. Indeed, certain individual tendencies or collective movements, such as panic phenomena, individualist reactions, the spread of rumours or distrust of the alert, can both hinder the response during a crisis, and have strong long-term consequences. These consequences can be diverse, psychological, political or economic for example, and make it difficult to return to a normal situation. 


\subsection{Be resilient}

Several concepts such as the resilience of populations or community resilience have emerged in recent years, accompanied in France by various initiatives such as the participation of populations in civil security exercises, in order to reinvest populations in crisis management.

The awareness of the challenges of resilience by French stakeholders has also resulted in concrete operational measures. These were notably initiated following the promulgation of the law of 13 August 2004 on the modernization of civil security. Indeed, this law encourages actions aimed at making the citizen responsible, going against the paradigm of "all protection" by the State, which in France has historically led to the idea that it was possible to protect, in absolute terms, the population. The ORSEC plan $^{1}$ now revolves around a common and simplified crisis management organization, accompanied by a risk inventory. Thus, efforts have been made in terms of institutional communication, through a redesign of the warning system in particular, by the integration of digital tools, and through increasingly diversified communications on institutional sites, but also on social networks more recently. It should be noted that for a long time, the foundations of the crises cause controversies/polemics, for many, still topical [5] and recurring criticisms exist on the vulnerability of the territories and the search for responsible people to whom to do pay for the occurrence/consequences of disasters.

\subsection{Alert}

Before the second world war, the means to alert the populations vis-a-vis a major risk was the tocsin. It was then gradually replaced by sirens which, since 1948, have constituted the National Alarm Network (RNA). Unfortunately, the sirens are partly obsolete, do not cover the whole territory, do not make it possible to inform the populations and are not synchronized with all the other means of alert [6]. Note, however, that other means of alert, which are evolving with the development of communication tools, complete this network, such as automatic calling machines or sending emails, which allow, at a more local level, to alert the populations.

A warning system can only work effectively if the people receiving the alerts are able to respond appropriately [7]. The alerts must be delivered on time and reach the populations concerned, but they must also be able to be understood, accepted and triggered safeguarding behaviour.

\footnotetext{
${ }^{1}$ Organization of Civil Security Response
}

\subsection{Risk typologies}

Crises can be classified according to different typologies, depending on the nature of the risks to which they relate or according to the event to which they are associated. The information service of the French government ${ }^{2}$ proposes to classify the major risks in the following categories: terrorist threat, health risks, technological risks (industrial, nuclear, biological accident, etc.), natural risks (landslide, fire, flood, hurricane, earthquake, etc.), and cyber risks. Another typology is proposed by the State [8] which differentiates fixed (nuclear, industrial, large dams, etc.) and non-fixed technological risks (land, air, water pollution, etc.), rail, motorway, aeronautical, river, maritime (land interface), natural and health risks. Finally, the classification of the Institute for Radioprotection and Nuclear Safety (IRSN) ${ }^{3}$ recognizes, for its part, four main risk groups, according to the perceptions of the French (relating to the perceived importance of the risk, trust in the French authorities and the perceived veracity of the information received) [9]: individual risks (e.g. smoking and obesity among young people, drugs, etc.), risks relating to diffuse pollution (e.g. air or water pollution, soil pollution, etc.), non-industrial collective risks (e.g. domestic accidents, heat waves, etc.) and technological risks attached to identifiable sites and actions (e.g. food products, chemical installations, etc.).

In this article, we are particularly interested in industrial risks.

\section{Crisis management in France}

The organization of crisis management in France is based on the principle of subsidiarity, it is based on the municipal, departmental and national levels. The decision to trigger the alert falls within the exercise of a general administrative police power, in accordance with the legal and regulatory provisions in force. The alert is part of a set of measures to protect populations, closely linked to crisis management. During a rescue operation, alerting is one of the responsibilities associated with the direction of rescue operations (DOS). It is, except in exceptional cases, exercised by the Mayor within the framework of his powers of general administrative police or by the Prefect ${ }^{4}$. The mayor is the common law authority responsible for making the decision to trigger the alert, in accordance with article L.2212-2-2 of the General Code of Local Authorities. The jurisprudence

\footnotetext{
${ }^{2}$ www.gouvernement.fr/en

${ }^{3}$ www.irsn.fr/EN

${ }^{4}$ https://en.wikipedia.org/wiki/Administrative_divisions_of_France
} 
of the Council of State specifies the field of intervention of the mayor by establishing that it falls to the mayor, under his powers of general police, to prepare the crisis situations likely to arise on the territory of his commune, and in particular to implement the alert and information measures for the populations (decision of the Council of State of June 22,1987). The municipal backup plan sets the organization necessary for the dissemination of the alert and safety instructions. The prefect of department also has competence in the matter which intervenes in certain cases (danger on the territory of several communes within the same department, failure of the mayor, event which exceeds the capacities of the commune, event of vast scope that justifies him to take the lead in relief operations). When the prefect is at the origin of the triggering of the alert, the mayor can be brought to supplement its diffusion by all the means at his disposal (megaphones, panels with variable message, diffusion of e-mails, etc). Finally, at national level, the Prime Minister (Title III of the Constitution), the Minister of Defence and the Minister of the Interior (Articles L.1142-1 and L.1142-2 of the Defence Code), have the possibility of deciding on the triggering of alert measures. In all consistency, these interventions are generally limited to particularly serious situations concerning a large geographic area. In any event, whatever the authority vested with the power to decide on the alert, the latter is free to choose the vectors of dissemination of this alert. The obligation attached to this mission is an obligation of result, not to resort to particular means.

\subsection{Decision in crisis management}

The urgency of a crisis situation means that the decisions taken to deal with it must be swift and effective. To respond to this, crisis units are set up to bring together the relevant stakeholders. Within a crisis unit, decisions are conditioned by strong uncertainties, a high number of stakeholders, sometimes extremely short periods of time to implement actions, communication problems, and important issues far exceeding the only immediate operational aspects [10]. The decisions mainly concern the choice of actions to be carried out and the resources to be allocated to these actions. They are regularly reassessed according to the evolution of the situation, by a new cycle of questions. An isolated individual is of course not legitimate to make such decisions, even if his experience and skills are proven. Decisions are taken collectively, by a multiplicity of stakeholders. Although in the event of a crisis there is a single manager designated as the commander of rescue operations (COS), he must interact with interlocutors from different professional cultures, not always present in the same place. According to [11], this multiplicity of stakeholders almost automatically leads to an increase in the possibility of disagreements and delays, and in differences in the hierarchy of priorities. [4] also highlights this difficulty by evoking the growing role that the media play today thanks to the speed with which they have access to information. Their new status as full-fledged actors in the management of the crisis represents a test that can be "destabilizing" for decision-makers. Finally, decisions are not always consensus.

\subsection{SEVESO Companies}

Since 1982, the SEVESO directive ${ }^{5}$ requires States and businesses to identify the risks associated with dangerous industrial activities and to take the necessary measures. The industries classified as SEVESO sites are establishments whose quantity of dangerous products exceeds the thresholds set in the European SEVESO directive. Over the years, the framework of the directive has evolved and, in June 2015, it was the SEVESO III directive (directive 2012/18/EU of July 4, 2012) which entered into force. All sites, industrial or agricultural, potentially presenting a risk of causing pollution or nuisance, in particular for the surrounding populations, are qualified as Classified Installations for the Protection of the Environment (ICPE). SEVESO classified sites are among the ICPEs whose operation is subject to authorization by the prefect. A distinction is made between so-called "high threshold" installations which present a major risk and so-called "low threshold" installations for which the risk is classified as significant. The prefect is the public authority in charge of the police of SEVESO classified installations. He gives, among others, the authorizations for operation and the operating conditions. Moreover, these installations are inspected and controlled by state agents of the Regional Directorates for the Environment, Development and Housing $\left(\mathrm{DREAL}^{6}\right)$ throughout their existence to verify that safety conditions are met.

Among the new features of the SEVESO III directive, we can cite the strengthening of the provisions relating to public access to useful information in terms of security. Residents living near SEVESO installations must therefore have direct access, via Internet, to information, prevention programs and emergency measures. In addition, SEVESO III requires all SEVESO companies at high risk of accident to organize a civil security exercise every three years.

\footnotetext{
${ }^{5}$ https://eur-lex.europa.eu/legal-content/EN/TXT/HTML/?uri= CELEX:31982L0501\&from=FR

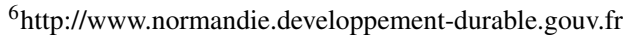




\section{The Lubrizol factory}

In this article, we are interested in a particular SEVESO installation: the Lubrizol factory in Rouen ${ }^{7}$ (France) which recently faced a major fire.

\subsection{Presentation}

Since 1954, Lubrizol France ${ }^{8}$, whose head office is based in Rouen, has been developing its activity of manufacturing and selling additives for lubricants. With its three production sites based in Rouen, Le Havre and Mourenx ${ }^{9}$, Lubrizol France is the main foreign subsidiary of the Lubrizol Corporation Group and the leading exporter from Haute-Normandie ${ }^{10}$. The company is certified Quality, Environment and Health/Safety. The Rouen industrial site also hosts a large part of the European support services (Supply Chain Europe, purchasing, finance and IT), as well as Lubrizol Holdings France and the headquarters of Lubrizol Advanced Material France. Lubrizol is committed to following the "Responsible Care global charter" to ensure and continuously improve the safety of its environment, people and facilities. The Lubrizol factory in Rouen is located on 14 hectares of an industrial-port area, south-west of Rouen, mainly in the city of Rouen, but also in Le Petit-Quevilly ${ }^{11}$ [12]. The Rouen site has been subject to the European SEVESO "high threshold" directive since 2009. Three types of risk have been identified: (i) fire, due to the flammable nature of the products stored; (ii) toxic dispersion, due to the thermal decomposition of certain products, the combustion of a liquid layer, or the spillage of toxic products; (iii) explosion, due to the formation and ignition of flammable vapors, triggering a deflagration. For public information, Lubrizol is attached to a site monitoring commission (Decree of February 7, 2012), composed of representatives of the State, local authorities, manufacturers, environmental protection associations, residents and employees [13]. There is also the Departmental File of Major Risks (DDRM) and the Municipal Information Document on Major Risks (DICRIM) in order to inform citizens preventively about the risks. The Particular Zone Intervention Plan (PPI) presents the risks of the 20 companies concerned by the PPI of the Rouen West zone [14].

\footnotetext{
${ }^{7}$ https://en.wikipedia.org/wiki/Rouen

${ }^{8}$ https://france.lubrizol.com/en/

${ }^{9}$ Rouen and Le Havre are cities in the North West of France (Normandy) and Mourenx is in the South West.

${ }^{10}$ https://en.wikipedia.org/wiki/Upper_Normandy

${ }^{11}$ Le Petit-Quevilly is located in Normandy in the Seine-Maritime department. Bordering on Rouen (and the Lubrizol factory), it is the 7th town in the department with 22,089 inhabitants. The town is located on the left bank of a meander of the Seine river. https://en.wikipedia.org/wiki/Le_Petit-Quevilly
}

\subsection{Background}

The Lubrizol factory in Rouen has experienced various crises.

- 1974 and 1989: Significant leak of Mercaptan (little known at the time by the general public) ${ }^{12}$. In 1974 and 1989, residents have to leave their homes, information is lacking and risks are unknown, the SEVESO directive does not yet exist.

- 2013 : Large Mercaptan leak. An unpleasant odour is perceived as far as the Paris region and in the south of England. The odour was perceived at extremely low concentrations, far below the regulatory toxicity threshold, there was no danger to health, but lack of clear information from the public, the incident caused panic ${ }^{13,14}$. A specific intervention plan is triggered (preventively). It allowed the authorities to supervise the removal of the product and the cleaning of the tanks [15]. The company is taking corrective action. The State is also reacting: Minister Delphine Batho announced, in April 2013, about twenty reinforced security measures for SEVESO sites, as part of a mobilization plan for the prevention of technological risks. One of these measures is the creation of a rapid intervention force that can quickly mobilize experts and resources from other industrial sites, and call on independent laboratories and associations to quickly measure the level of accidental releases ${ }^{15}[16,17]$. Legal and ministerial investigations are carried out and Lubrizol sanctioned ${ }^{16}$.

- 2015: Following an operational incident, 2,000 liters of mineral oil are discharged into the rainwater drainage system. A dam is put in place to avoid any diffusion in the Seine river.

- 2017: A prefectural decree for formal notice for insufficiency of the fire-fighting system is taken concerning the factory ${ }^{17}$.

\footnotetext{
${ }^{12}$ Methanethiol, or methylmercaptan, is an organosulfur compound. It is a foul-smelling colourless gas (whose smell is reminiscent of rotten cabbage). It is a natural substance that can be found in the blood, brain and other tissues, animal or human.

${ }^{13}$ Agnès Rousseaux and Ivan du Roy, Toxic gas in Rouen: have the authorities been lax?, January 22, 2013, (French) https://www.bastamag.net/Gaz-toxique-a-Rouen-les-autorites

${ }^{14}$ Lubrizol affair: the overwhelming report, July 18, 2013, (French) https://www.francebleu.fr/affaire-lubrizol-le-rapport-accablant-1374155004

${ }^{15}$ Laurent Radisson, Industrial risks: the three measures of the Batho plan, April 11, 2013, (French) https://www.actu-environnement.com/ae/news/risques-industriels-PPRT-force-interventionrapide-Seveso-18261.php4

${ }^{16}$ Lubrizol factory in Rouen: already in 2013, a gas leak and sanctions, September 26, 2019, (French) https://www.francetvinfo.fr/faits-divers/incendie/incendie-d-un-site-seveso-a-rouen/usinelubrizol-de-rouen-en-2013-deja-une-fuite-de-gaz-et-des-sanctions_3632785.html

${ }^{17}$ Fire at the Lubrizol factory, September 26, 2019, (French)
} 
It should be noted that, although some incidents can happen, when they are repeated and sanctioned, this is worrying (especially from population's point of view).

\section{September 26, 2019 fire}

A fire broke out on September 26, 2019 in the Lubrizol factory ${ }^{18}$. As a result, a thick plume of black smoke formed, reaching more than $20 \mathrm{~km}$. The first day is devoted to controlling the fire and implementing measures to protect the population and the environment. The authorities, who communicate, want to be reassuring in view of the first measurements carried out. However, public fears both in terms of health and environment are growing and public speaking is difficult to hear. The publication, on October 1, 2019, of the list of products on site does not help reassure the public to such an extent that before the end of the first week following the event, the court of Rouen is seized of several complaints, a parliamentary information mission is created, the dissatisfaction of several impacted professions is expressed in various ways.

Fire started

A fire broke out on Thursday, September 26, 2019 at around 3:40 a.m. within the Lubrizol factory hitting the barrel crushing and storage facilities as well as a nearby warehouse belonging to the company SCMT (Shopping and transport company) ${ }^{19}$. The formal origin of the fire has not been established. In a press release the official website of the industrial group hypothesizes that it may be external to the site ${ }^{20}$

Crisis unit

The prefect of Seine-Maritime immediately triggers the Particular Zone Intervention Plan (PPI) and opens a departmental operational centre (COD) in the prefecture to manage the event. A Public Information Centre (CIP) is also installed in the prefecture, with a free telephone number. At 3 p.m., the CIP had recorded more than 1,200 calls $^{21}$. At the same time, the municipalities concerned, once informed, also initiate their PPI and respectively set up a crisis unit. For the commune of Le Petit-Quevilly, the chronology is as follows ${ }^{22}$ :

https://www.alternative76.fr/2019/09/26/incendie-de-l-usine-lubrizol-contexte-bilan-ett\%C3\%A9moigages/

${ }^{18} \mathrm{https} / / / \mathrm{fr}$.wikipedia.org/wiki/Chronologie_de_1\%27incendie_de _1\%27usine_Lubrizol_\%C3\%A0_Rouen_and_de_ses_cons\%C3\% A9quences, (French)

${ }^{19}$ Fire at Lubrizol Rouen, France, https://www.lubrizol.com/Rouen/Company-Statements

${ }^{20}$ Fire in Rouen: the Lubrizol company is filing a complaint for involuntary destruction, September 30, 2019, Le Monde, (French) https://www.lemonde.fr/planete/article/2019/09/30/rouen-lubrizol-porte-plainte-pourdestruction-involontaire-par-explosion-ou-incendie_6013671_3244.html

${ }^{21}$ Fire at the Seveso de Lubrizol site in Rouen: relive the day minute by minute, September 26, 2019, Ouest France, (French) https://www.ouest-france.fr/normandie/rouen-76000/rouen-explosions-et-gigantesque-incendiedepuis-3-h-du-matin-sur-le-site-classe-seveso-de-lubrizol-6537195

${ }^{22}$ Sébastien Bailly, Factory fire Lubrizol: the anger of the
- 4:15 a.m.: National Police telephone call to the on-call manager of the city, informing of the accident (having started around 3:40 a.m.) and requesting the installation of a security barrier of the perimeter concerned, the manager informs the Director General of the factory, which informs the mayor of Petit-Quevilly, and the head of the security service.

- 4:45 a.m.: the on-call manager of the city is in front of the burning factory.

- 5:00 a.m.: residents closest to the site are confined to their homes by the police and fire-fighters.

- 6:00 a.m.: a crisis unit is in place at the town hall.

Population alert

At 6:11 a.m., the city of Petit-Quevilly uses its SMS and voice call alert system to which residents who wish to subscribe $\left(6,770\right.$ households $\left.^{23}\right)$. Some residents close to the factory got scared from 5:15 a.m. - 5:30 a.m. At 7:10 a.m., the Seine-Maritime prefecture announces that it will set off the sirens at 7:45 a.m. to alert the population. At 8 a.m., the siren sounds in the Rouen metropolitan area. It seems that not everyone has heard these sirens ${ }^{24}$. The commune/town hall of Le Petit-Quevilly relays via Tweeter at 7:30 a.m. the information of confinement of the population within a radius of $500 \mathrm{~m}$ around the site and closure of schools. At 7:37 a.m., the City of Rouen puts out a press release on its website. At 9:30 a.m., an information number is distributed by the Seine-Maritime prefecture. Around 10 a.m., the prefect of Seine-Maritime tries to reassure by indicating that there is no toxicity and that precautionary measures have been taken.

First measures to protect people and the environment

Between the triggering of the PPI and the measures requested by the prefecture, we can cite ${ }^{25,26}$ :

- Shut-down of site activities, requiring the shut-down of site activities and its security and requiring the operator to secure its site (collect and evacuate polluted water following the fire, evacuate waste) and ensure the necessary actions

mayor of Petit-Quevilly, September 28, 2019, Ouest France, (French) https://www.ouest-france.fr/normandie/rouen-76000/incendie-de-l-usine-lubrizol-la-colerede-la-maire-de-petit-quevilly-6541107

${ }^{23}$ Cédralis, alert system by telephone, (French) http://www.petit-quevilly.fr/mairie/actualites/cedralis-systeme-d-alerte-par-telephone-710.htm

${ }^{24}$ Valentin Ehkirch, What protocols for people living near a Seveso site?, September 29, 2019, L'Express, (French) https://www.lexpress.fr/actualite/societe/quelles-mesures-pour-proteger-les-populations-situeesautour-d-un-site-seveso_2100349.html

${ }^{25}$ Fire at the Lubrizol factory - Chronology of events, September 26, 2019, Le Parisien, (French) https://www.leparisien.fr/faits-divers/direct-rouen-12-communes-confinees-apres-desexplosions-et-un-incendie-dans-une-usine-chimique-26-09-2019-8160069.php

${ }^{26}$ Claire Grenier, The fire of a factory in Rouen revives the debate on the fight against industrial risks, September 26, 2019, Les Echos, (French) https://www.lesechos.fr/industrie-services/industrie-lourde/lincendie-dune-usine-a-rouenrelance-le-debat-sur-la-lutte-contre-les-risques-industriels-1135101 
guaranteeing the absence of intrusion on site and controlling access.

- Installation of a security barrier to protect the defined containment perimeter of $500 \mathrm{~m}$ and traffic restrictions accordingly.

- Dissemination of advice to the population.

- Closure of schools, nurseries, etc. on September 26 and 27.

- Recommendations to breeders and farmers.

- Triggering of the Polmar plan, a device triggered in the event of accidental maritime pollution, which notably provides for the installation of anti-pollution dams.

\section{Population interviews}

Following this fire, we interviewed the population of the Rouen agglomeration using a questionnaire (adapted from [18]). The objective of this study was to obtain, among other things, information on the reactions of people to the warning signals triggered during the fire at the Lubrizol factory on September 26, 2019. The 77 ("open" and "closed") questions in this survey were voluntarily very open to let people express themselves freely, allow them to reflect on their reactions. The study was therefore carried out from an anonymous survey posted online from 06 December 2019 to 06 January 2020. It was created using Google Form ${ }^{27}$ for the creation of online forms and distributed via the Facebook social network. The Facebook group "Collectif Lubrizol" was chosen as a relay for the dissemination of the survey. Founded in the day after the fire started, the group had almost 25,500 members in April 2020. Although no sociological survey has been conducted on this interest group, we have observed a great diversity of profiles.

It should be noted that more and more researchers are turning to online survey methods to collect data. The concept of online survey is generally opposed to more conventional/traditional methods of polling by mail, telephone or face-to-face. However, there is no universal definition of what constitutes an online survey. [19] uses this term to designate surveys where respondents are not only recruited via Internet but must also complete an online questionnaire. [20], for its part, include any survey method involving Internet during the dissemination, sampling or design of the survey. Finally, sometimes the conceptual framework can be ambiguous, as in the case of [21] who defines an online survey as a survey carried out via a website.

Like traditional surveys, online surveys must recruit participants. There are two modes of recruitment:

\footnotetext{
${ }^{27}$ https://www.google.fr/intl/en/forms/about/
}

(i) probabilistic, where participants are chosen and targeted so that the results are generalizable to a wider population of interest and (ii) non-probabilistic, where the probability that a individual from a population of interest belonging to the sample is unknown [19]. In the case of a probabilistic online survey, it is possible to control the sampling by only distributing the questionnaire to a closed list of email addresses, or by recruiting participants by more traditional methods (phone, face-to-face, etc.) and by providing them with Internet access if necessary to respond to the questionnaire [19, 21]. Conversely, during an online survey with non-probabilistic recruitment, the sampling is not controlled (e.g. invitations to the survey posted on platforms and then relayed via social networks without supervision, etc.). [22] names the latter, which corresponds to our own survey method, "unrestricted self-selection survey". According to [19], the corresponding sampling method is known as "river sampling".

The use of online survey with non-probabilistic recruitment has many advantages (e.g. decorrelation of survey costs from sample size, reduction of collection times and geographic constraint, etc.) [21] but also disadvantages (e.g. coverage error linked to the digital divide and self-selection of respondents). Many studies, including [23], show that regular users of social networks are hardly representative of the national population. Thus, the use of social media as a dissemination platform can considerably bias the representativeness of a sample of respondents. However, traditional survey methods also come up against problems of coverage and exclusion (e.g. quality of the telephone network, etc.). In all cases, generalizing to a larger population the results of studies obtained from a sample of non-probabilistic respondents requires a precise understanding of the socio-demographic differentiation operated by these different coverage filters. However, in the case of online survey methods using river sampling, these sources seem to be still poorly understood, making the results difficult to generalize and vulnerable to possible misappropriation [19]. To the bias induced by the exclusion of less connected individuals is added the self-selection bias originating from a non-probabilistic recruitment mode. One speaks of self-selection when respondents choose to participate in a survey themselves. It is therefore a frequent occurrence in the survey world, which is not limited to the case of online surveys. The research carried out on this subject present certain points of consensus: the self-selected respondents are more interested in the subject treated than the rest of the population, feel more concerned, and are more 
likely to have strong opinions concerning the themes of the survey [20, 24]. Unfortunately, if these trends are commonly identified, many authors note that it is difficult to correct the biases induced by uncontrolled voluntary participation $[22,24]$.

It should be noted that the biases identified in our survey do not impact the quality/validity of the results but give some characteristics of the respondents: people involved who use social media - which is not generalizable.

As part of our online survey with non-probabilistic recruitment, we collected information on the age, sex, professional category and place of residence of the participants, who then answered various questions relating to the information received, the actions carried out, the perception of the alerts, the feelings towards the fire, past experiences and their vision of crisis management by public policies.

\section{Analysis}

A total of 237 people responded to the online survey. About $56 \%$ of the respondents are between 25 and 50 years old, $39 \%$ are over 50 years old and only $5 \%$ are less than 25 years old. This low participation of those under 25 may seem unusual since the questionnaire was disseminated via a social network, but perhaps we can partly explain it by the fact that the questionnaire was accessible during a school holiday period (Christmas). The rest of the population is fairly well represented. This distribution is shown in Figure 1. Furthermore, as shown in Figure 1, among the 237 people questioned, 93 live in Rouen and 119 live less than $15 \mathrm{~km}$ around Rouen. It should also be noted that the people living in the fire area were not the only ones to have answered the questionnaire. This shows a real involvement of the populations (impacted or not). Finally, Figure 1 shows that women represent more than $70 \%$ of the respondents.

We are focusing here on an open question that was asked at the end of the questionnaire: "In your opinion, what could have been done differently?". We have analysed the answers to this question (which constitute our dataset) syntactically, using the free software IRaMuTeQ ${ }^{28}$. Figure 2 gives some descriptive statistics relating to our dataset. Among the 237 respondents to the questionnaire, only 158 answered the question studied here and there are 1183 different terms.

A first analysis of the terms used, represented via the tag cloud ${ }^{29}$ of Figure 3, reveals that the respondents used the terms disaster, security, population, risk, odour, state which show their main concerns about the security

\footnotetext{
${ }^{28} \mathrm{R}$ interface for Multidimensional Text and Questionnaire Analysis. http://www.iramuteq.org/

${ }^{29}$ In a tag cloud, the more a word is visible, the more it is recurrent in the text/document.
}

and risk of the populations but also about the implication of the State. Other terms like life, management, health, public, fire-fighter, trust, authority, accident, information, dangerous, shameful testify to the diversity of the subjects covered but also to a certain fear/anger.

The analysis of the keywords by gender of the respondents ${ }^{30}$ showed that, whatever the gender, no keyword is used more than another. Regarding the age of the respondents, the most frequent keywords by age group are:

- Under 25: management, victim, population, accident, dangerous, inform which testify to the awareness of the risk for the populations but also to the need for information.

- Between 25 and 30 years old: default, smell, pollute, politics which testify to an observation of their daily experience (the odours of Mercaptan are strong and slow to fade) and a negative judgement of public decisions.

- Between 30 and 40 years old: shameful, consequence, worry, feeling, health, future, risk, responsible who also testify to a negative judgement of public decisions but in addition to the search for responsible of the fire.

- Between 40 and 50 and Over 60: confidence, crisis, danger, alert, child, security, anger which testify to anger and a loss of confidence in the public authorities.

- Between 50 and 60 years old: authority, lie, fire-fighter, fire, pollution, cancer, communication which also testify to a loss of confidence in the public authorities but also to a need for communication.

These analyses reveal that the respondents, as population for the majority directly impacted by this disaster, suffer from annoyances (odour) but are aware that there are risks and a need for security and that the State is a stakeholder in the management of the crisis. Respondents seem worried about their health and reveal a certain dissatisfaction with the public authorities (lack of trust, dangerous, shameful).

Some of these interpretations are also found in Figure 4 which presents the detection of communities in the keyword graph. Seven communities appear:

1. Population: With keywords representative of the concerns of the population, such as smell, child, health, confidence, etc.;

2. Disaster/Fire: With keywords like shameful, etc. which imply that this fire should not have happened;

${ }^{30}$ For the sake of space, all the graphics produced are not exposed in the article. 


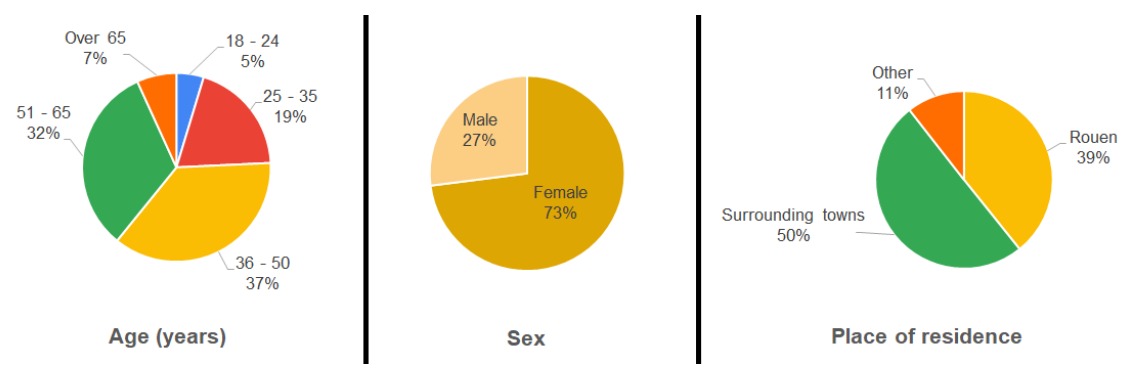

Figure 1. Distribution of respondents

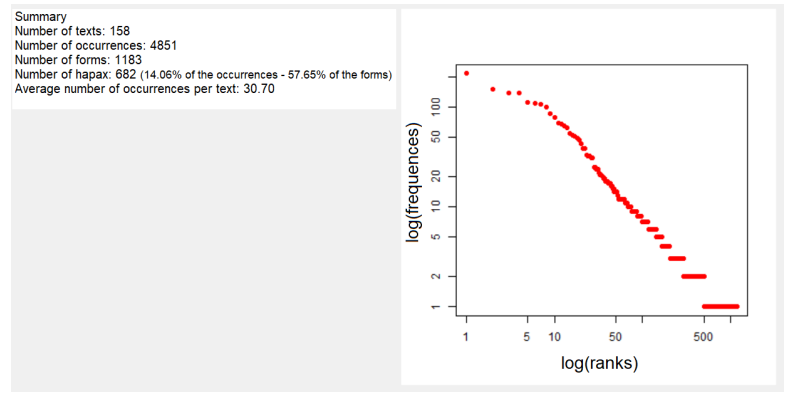

Figure 2. Descriptive statistics

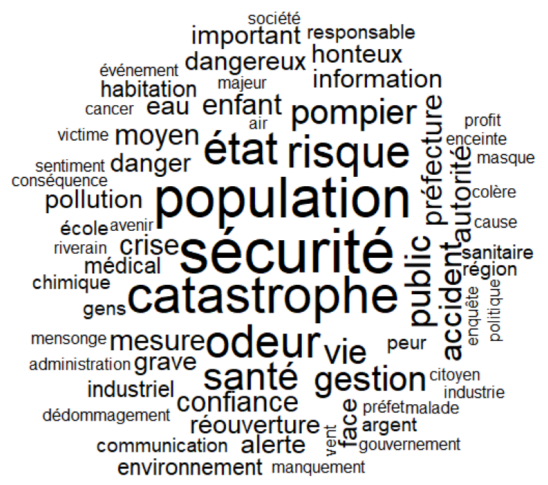

Figure 3. Tag cloud (security, population, disaster, risk, State,

odour, health, fire-fighters, etc.)

3. Factory: Where keywords like risk, communication, information, anger, dangerous, etc. suggest that the respondents would have liked more communication/information on the dangerousness of the factory in particular;

4. City: Keywords like pollution, cancer, air, etc. indicate that respondents are concerned about the impact of the fire on the city and its surroundings;

5. Security/Business: Respondents incriminate the public authorities with keywords such as prefecture, default, measures, etc.;
6. Crisis management: The question is still topical with regard to the aftermath of the fire, particularly with the reopening (possibly partial) of the Lubrizol factory (reopening, prefect, etc.);

7. Site: Keywords like citizen, fire-fighters, housing, etc. indicate that the respondents are concerned about the impact of the fire around the factory and how the emergency services responded.

The results of this study are of course specific to the environment of the Lubrizol factory in Rouen. It appears that depending on the age and place of residence, in particular, the expectations/feelings of the respondents are different. It will therefore be difficult to provide a single homogeneous response to all. However, we observe that they provide first elements to realize the lack of confidence and mistrust of the populations towards the decisions of the public authorities during a crisis. Indeed, in light of the analysis of the responses to the question "What do you think could have been done differently?" during the fire at the Lubrizol factory in Rouen on September 26, 2019, it was fairly clear that the respondents criticized the decisions/actions of the public authorities in managing the crisis. This results in a lack of confidence and anger towards decision-makers. This distrust hinders resilience ${ }^{31}$ in the area affected by the crisis. It should be noted that this distrust was not noted only during this fire and that it is the subject of many discussions $[25,26]$ and of the political confidence barometer [27].

\section{How to reconcile populations and decision-makers?}

The mistrust of populations towards public policies can be explained by the fact that: (i) citizens are more and more qualified and therefore more and more capable of taking an interest in debates and giving their opinion,

\footnotetext{
${ }^{31}$ Here, this is community/collective resilience which is the capacity of a community to continue to live, function, develop and flourish after a trauma or disaster.
} 


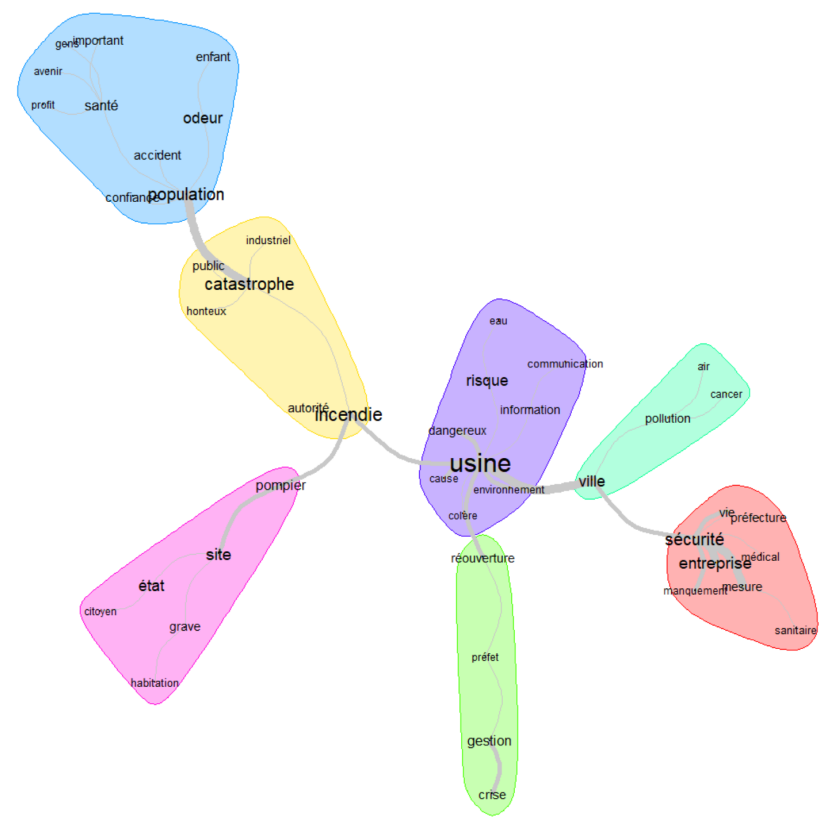

Figure 4. Detecting communities in the keyword graph (blue: population, odour, health, etc.; yellow: disaster, fire, etc.; pink: State, fire-fighter, etc.; violet: factory, risk, etc.; light green: crisis, prefect, reopening, etc.; green: city, pollution, etc.; red: company, security, etc.)

(ii) numerous scandals have tarnished the confidence of populations (contaminated blood, Chernobyl, etc.), (iii) France's growth is slowing down, which raises doubts about the effectiveness of public authorities'decisions, (iv) digital and social networks weaken the credibility of experts (political, scientific, etc.) [26]. Finally, it is not a question of gaining the confidence of the populations but rather to do with distrust and to incorporate it into the (information) system for more openness, relevance and robustness.

We list a few other ways to try to reconcile the people and decision-makers:

- Ability to answer questions from populations.

- Transparency of the decision-making process, itself linked to:

- Explainability of the decision process, i.e. the ability to explain how the system works. This explainability must not be the subject of an a posteriori attempt but be taken into account during the system design phase in order to guarantee better understanding;

- Responsibility, decision-makers must be able to justify the choices made.

- Reconciliation of cultures: "popular" cultures, public speaking and scientific culture.

Today there are many (information) systems allowing decision-makers to make decisions (decision-making aid, decision-making systems (recommendations, etc.), etc.) increasingly user-centric. However, Big Data, Machine Learning and Artificial Intelligence allow "automatic" decision-making, but such objective approaches risk leaving no room for debate. It seems that, in addition to the decision taken, the populations expect in particular more transparency and therefore explanations as to the decisions taken. Many (computer) systems today are capable of helping decision-making, faster and faster and more and more "efficiently" (neural networks, etc.) unfortunately, many of these systems suffer from transparency, i.e. of accountability and explainability, which would reconcile decision-makers and populations. It is also important to note that all these systems need a lot of data to be effective, and, fortunately, disasters are not too frequent (especially in the same place for the same hazard, thanks to the experience acquired in particular). Thus, the data available is therefore not sufficient for these systems/tools to be effective. In addition, in fine, the decision remains "human".

\section{Conclusion}

In this article, we are interested in crisis management and, in particular, in the distrust that people may have towards public authorities and their decisions. Following the fire at the Lubrizol factory, classified SEVESO, in Rouen (France), on September 26, 2019 (industrial accident), we were 
able to interview the population through an online questionnaire. The analysis of a specific question in this questionnaire relating to the decisions taken to manage this crisis made it possible to highlight the distrust of the population towards public decision-makers. Finally, we have proposed ways to improve existing decision-making support systems and try to identify the characteristics that an (information) system should have in order to reconcile populations and decision-makers (transparency, explainability, etc.).

Among the 77 questions of our survey, we have analysed here only one of them. The results obtained are a first step towards reconciliation between the populations and the decision-makers. A complete analysis will allow us to make some implications and recommendations (for example, regarding the actions of decision-makers or community engagement).

Many lines of research are possible on the basis of our reflection, in particular, as to the expected characteristics of an information (and knowledge) system. This work should be transverse to the scientific community involving, among others, data processing concepts, knowledge management, gender, culture, public policy analysis, etc. Finally, further discussion should also be conducted on the information to be disseminated and the means to do so, depending on the target population or the information to be transmitted.

Acknowledgement : We thank all the participants in this survey for the time they devoted to it and their involvement.

\section{References}

[1] C. Lattimer and S. Swithern, "Global humanitarian assistance report," 2017. Development Initiatives, Somerset, UK.

[2] J.-C. Gaillard and J. Mercer, "From knowledge to action: Bridging gaps in disaster risk reduction," Progress in human geography, vol. 37, no. 1, pp. 93-114, 2013.

[3] INSEE, "Economic players and the environment," 2017.

[4] P. Lagadec, Preventing Chaos in a Crisis - Strategies for Prevention, Control and Damage Limitation. 1993.

[5] F. Dedieu, Une catastrophe ordinaire. La tempête du 27 décembre 1999. Cas de figure, Les Éditions de l’École des hautes études en sciences sociales, May 2013.

[6] DGSCGC, "Guide orsec - alerte et information des populations. direction générale de la sécurité civile et de la gestion des crises," 2013. Ministère de l'Intérieur.

[7] H. Kreibich, M. Müller, K. Schröter, and A. H Thieken, "New insights into flood warning reception and emergency response by affected parties," Natural Hazards and Earth System Sciences, vol. 17, no. 12, pp. 2075-2092, 2017.

[8] DGSCGC, "Guide orsec - méthode générale. direction générale de la sécurité civile et de la gestion des crises,' 2006.
[9] BVA, "Irsn barometer 2019 - the perception of risks and security in france." http://barometre.irsn.fr, 2019.

[10] P. Lagadec, Cellules de crise: Les conditions d'une conduite efficace. Direction générale, Les Editions d'organisation, 1995.

[11] J. Pressman and A. Wildavsky, Implementation: How Great Expectations in Washington Are Dashed in Oakland; Or, Why It's Amazing that Federal Programs Work at All, This Being a Saga of the Economic Development Administration as Told by Two Sympathetic Observers Who Seek to Build Morals on a Foundation. Oakland Project series, University of California Press, 1984.

[12] J. Fontaine and B. Mignot, "Rapport du commissaire enquêteur sur le plan de prévention des risques technologiques à l'usine lubrizol," 2014. Préfecture de Seine-Maritime.

[13] Seine-Maritime, "Plan de prévention des risques technologiques autour de l'entreprise lubrizol - note de présentation," 2014. Préfecture de Seine-Maritime.

[14] Seine-Maritime, "Plaquette présentant le ppi de la zone ouest de rouen," 2016. Préfecture de Seine-Maritime.

[15] Seine-Maritime, "Dossier départemental des risques majeurs," 2014. Préfecture de Seine-Maritime.

[16] DD, "Extended release of mercaptans from a chemical plant - 21/01/2013 - france - 76 - rouen." https://www.aria.developpement-durable.gouv.fr, 2013. Ministère du Développement durable.

[17] TES, “Circulaire du 11/04/13 relative à l'élaboration et la mise en oeuvre des plans de prévention des risques technologiques (pprt)," 2013. Ministère de la Transition Ecologique et Solidaire.

[18] M. Arru, Introduction of knowledge relating to the behavior of populations in early warning systems. $\mathrm{PhD}$ thesis, Universite Paris-Dauphine, France, 2019.

[19] V. Lehdonvirta, A. Oksanen, P. Rasanen, and G. Blank, "Social media, web, and panel surveys: Using non-probability samples in social and policy research," Policy \& Internet, 2020.

[20] Y.-H. Hwang and D. R. Fesenmaier, "Coverage error embedded in self-selected internet-based samples: A case study of northern indiana," Journal of Travel Research, vol. 42, no. 3, pp. 297-304, 2004.

[21] C. Durand, "Internet polls: New and revisited challenges," 2013.

[22] R. Bigot, P. Croutte, and F. Recours, "Is it possible to extrapolate behaviors of internet-users to the general population?," Cahier de Recherche, CREDOC, vol. C, $273,2010$.

[23] J. Mellon and C. Prosser, "Twitter and facebook are not representative of the general population: Political attitudes and demographics of british social media users," Research \& Politics, vol. 4, no. 3, 2017.

[24] D. Frippiat and N. Marquis, "Web surveys in the social sciences: An overview," Population, vol. 65(2), pp. 285-311, 2010.

[25] C. Chognot, "Expertise and democracy. coping with mistrust," 2019. Rapport de France Stratégie.

[26] J.-G. Plumelle, "Pour une société de confiance. quel rôle pour le service public ?," 2019. Action Publique num.4.

[27] M. Cheurfa and F. Chanvril, "2009-2019 : la crise de la confiance politique,” 2019. 